University for Business and Technology in Kosovo

UBT Knowledge Center

UBT International Conference

2015 UBT International Conference

Nov 7th, 9:00 AM - 5:00 PM

\title{
Optimal Control of DC Motors Using PSO Algorithm for Tuning PID Controller
}

Arnisa Myrtellari

Polytechnic University of Tirana, arnisa84@live.com

Petrika Marango

Polytechnic University of Tirana, petmara@yahoo.com

Margarita Gjonaj

Polytechnic University of Tirana, margarita.gjonaj@yahoo.com

Follow this and additional works at: https://knowledgecenter.ubt-uni.net/conference

Part of the Robotics Commons

\section{Recommended Citation}

Myrtellari, Arnisa; Marango, Petrika; and Gjonaj, Margarita, "Optimal Control of DC Motors Using PSO Algorithm for Tuning PID Controller" (2015). UBT International Conference. 40.

https://knowledgecenter.ubt-uni.net/conference/2015/all-events/40

This Event is brought to you for free and open access by the Publication and Journals at UBT Knowledge Center. It has been accepted for inclusion in UBT International Conference by an authorized administrator of UBT Knowledge Center. For more information, please contact knowledge.center@ubt-uni.net. 


\title{
Optimal Control of DC Motors Using PSO Algorithm for Tuning PID Controller
}

\author{
Arnisa Myrtellari ${ }^{1}$, Petrika Marango ${ }^{2}$, Margarita Gjonaj $^{3}$ \\ 1,2,3Polytechnic University of Tirana, Faculty of Electrical Engineering, Department of \\ Automation, Sheshi Nënë Tereza, Tiranë, Albania \\ arnisa84@live.com ${ }^{1}$, petmara@yahoo.com², margarita gjonaj@yahoo.com ${ }^{3}$
}

\begin{abstract}
The DC motors are widely used in the mechanisms that require control of speed. Different speed can be obtained by changing the field voltage and the armature voltage. The classic PID controllers are widely used in industrial process for speed control. But they aren't suitable for high performance cases, because of the low robustness of PID controller. So many researchers have been study ing various new control techniques in order to improve the system performance and tuning PID controllers. This paper presents particle swarm optimization (PSO) method for determining the optimal PID controller parameters to find the optimal parameters of DC Motor speed control system. The DC Motor sy stem drive is modeled in MATLAB/SIMULINK and PSO algorithm is implemented using MATLAB toolbox. The results obtained through simulation show that the proposed controller can perform an efficient search for the optimal PID controller. Simulation results show performance improvement in time domain specifications for a step response (no overshoot, minimal rise time, steady state error $=0$ ).
\end{abstract}

Keywords: Speed control, DC Motor, Particle Swarm Optimization

\section{Introduction}

The electric motor drive is widely used in industries. A large proportion of electrical energy is consumed by electric motors. Electric motors provide efficient, reliable, long-lasting service, and most require comparatively little maintenance. Despite these advantages, however, they can be inefficient and costly to operate if they are not properly selected and maintained. Industrial plants can avoid unnecessary increases in energy consumption, maintenance, and costs, by selecting motors that are well suited to their applications and making sure that they are well maintained. The high cost of energy has placed a premium on finding ways to reduce the energy consumption by equipment and systems in industrial applications. Presently, the energy saving is the interesting issue for the engineers. In spite of the development of power electronics resources, the direct current machine became more and more useful; the energy efficiency of its drive systems could be improved by reducing the energy losses in the system and by improving the efficiency of the motors. DC motors have long been the primary means of electrical traction. DC motor has at torque/speed characteristics compatible with most mechanical load. Control of DC motor speed by conventional PID controllers are well known and their objective is a good performance that include minimization of the steady state error, minimization of rise time and minimization of settling time. Proportional-Integral-Derivative (PID) controllers are a very efficient solution to obtain the desired output from the plant in steady state as well for dy namic response. Two classical methods that are still utilized are the Ziegler-Nichols and the Cohen-Coon which utilize analytical approaches for analysis and tuning PID parameters. A technique that is used for tuning PID parameters which is based on Swarm Optimization is the Particle Swarm Optimization (PSO) technique. A swarm consists of individuals called particles, each of which represents a different possible set of the unknown parameters to be optimized. The "swarm" is initialized with a population of random solutions. In a PSO particles fly about in a multi-dimensional search space adjusting its position according to its own experience and the experience of its neighboring particle. The goal is to efficiently search the solution space by swarming the particles towards the best fitting solution encountered in previous iterations with the intention of encountering 
better solutions through the course of the process and eventually converging on a single minimum or maximum solution. In this paper the optimal parameters of PID controller are proposed by using PSO algorithm method. Iterative simulation results shows that the effectiveness of Particle Swarm Optimization approach PSO since it allows the operator to find a near optimal good compromise among the proposed goals, which is best trade-off lowest cost PID controller design.

\section{Model of DC motor}

DC motor is a power actuator which transforms electrical energy in to mechanical energy. DC motor is widely used in many industrial applications where wide range of speed -torque characteristics required. In this paper, the separated excited DC motor model is chosen according to his good electrical and mechanical performances more than the other DC motor models. Fig.1 show the equivalent circuit of DC motor with separate excitation.

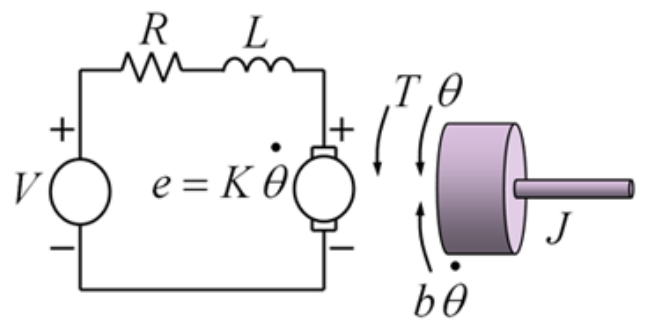

Fig.1 Equivalent circuit of DC motor

The dynamic equations of DC motor are given as follow:

$$
\left[\begin{array}{l}
\frac{d \omega}{d t} \\
\frac{d i}{d t}
\end{array}\right]=\left[\begin{array}{cc}
\frac{-b}{J} & \frac{k}{J} \\
\frac{-k}{L} & \frac{-R}{L}
\end{array}\right]\left[\begin{array}{c}
\omega \\
i
\end{array}\right]+\left[\begin{array}{c}
0 \\
\frac{1}{L}
\end{array}\right] u
$$


The transfer function of DC motor is:

$$
G(s)=\frac{\omega(s)}{U(s)}=\frac{k}{J L s^{2}+b L s+R b+k k_{b}}
$$

The parameters of the motor are shown in the Table.1:

Table.1 Parameter of DC motor

\begin{tabular}{|l|l|l|}
\hline $\mathrm{J}$ & Moment of Inertia of the Rotor $\left(\mathrm{kg} \mathrm{m}^{2}\right)$ & 0.01 \\
\hline $\mathrm{L}$ & Motor Electric Inductance $(\mathrm{H})$ & 0.5 \\
\hline $\mathrm{R}$ & Motor Electric Resistance $(\boldsymbol{\Omega})$ & 1 \\
\hline $\mathrm{b}$ & Damping Ratio of Mechanical System $(\mathrm{N} \mathrm{m} \mathrm{s})$ & 0.00003 \\
\hline $\mathrm{k}$ & Motor Constant $(\mathrm{Nm} / \mathrm{A})$ & 0.023 \\
\hline $\mathrm{k}_{\mathrm{b}}$ & EMF constant $(\mathrm{V} \mathrm{sec})$ & 0.023 \\
\hline
\end{tabular}

\section{PID controlle $r$}

PID controllers have been at the heart of control engineering practice for seven decades. The PID controllers have a wide range of ap plications in industrial control because of their simple control structure. The PID controllers need of less plant information than a complete mathematical model. The controller attempts to minimize the error by adjusting the process control input. The PID controller calculation (algorithm) involves three constant parameters called the proportional (P), integral (I), derivative (D) values, these value can be interpreted in terms of time. The transfer function of PID controller is:

$$
G_{c}(s)=k_{p}+\frac{k_{i}}{s}+k_{d} s=k_{p}\left(1+\frac{1}{T_{i} s}+T_{d} s\right)
$$

The Ziegler-Nichols design methods are the most popular methods used in process control to determine the parameters of a PID controller. The step response method is based on an open-loop step response test of the process. The step response of the process is characterized by two parameters $\mathrm{L}$ and $\mathrm{T}$ that are determined by drawing a tangent line at the inflexion point.

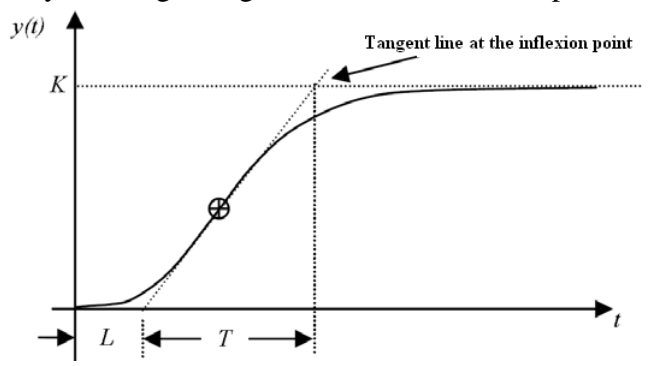

Fig.2

The intersections of the tangent and the coordinate axes give the process parameters as shown in Fig.2, and these are used in calculating the controller parameters. The parameters for PID controllers obtained from the Ziegler-Nichols step response method are shown in Table2. 
Table 2 PID parameters.

\begin{tabular}{l|c|c|c}
\hline Type of controller & $\mathrm{K}_{\mathrm{p}}$ & $\mathrm{T}_{\mathrm{i}}$ & $\mathrm{T}_{\mathrm{d}}$ \\
\hline $\mathrm{P}$ & $\mathrm{T} / \mathrm{L}$ & $\infty$ & 0 \\
$\mathrm{PI}$ & $0.9 \mathrm{~T} / \mathrm{L}$ & $\mathrm{L} / 0.3$ & 0 \\
$\mathrm{PID}$ & $1.2 \mathrm{~T} / \mathrm{L}$ & $2 \mathrm{~L}$ & $0.5 \mathrm{~L}$ \\
\hline
\end{tabular}

\section{Particle Swarm Optimization}

Particle Swarm Optimization (PSO) technique, proposed by Kennedy and Eberhart is an evolutionarytype global optimization technique developed due to the inspiration of social activities in flock of birds and school of fish and is widely applied in various engineering problems due to its high computational efficiencv. It has been proved to be an effective optimum tool in system identification and PID controller tuning for a class of processes. This techniques is used to minimize the maximum overshoot, minimize the rise time, minimize speed tracking error, minimize the steady state error, and minimize the settling time, optimization solution results are set of near optimal trade-off value which are called the Pareto front or optimally surfaces. PSO is a robust stochastic optimization technique based on the movement and intelligence of swarms. The components of PSO are Swarm Size, Velocity, position components and maximum no of iteration. The structure of the PID controller with PSO algorithm is shown in Fig.3.

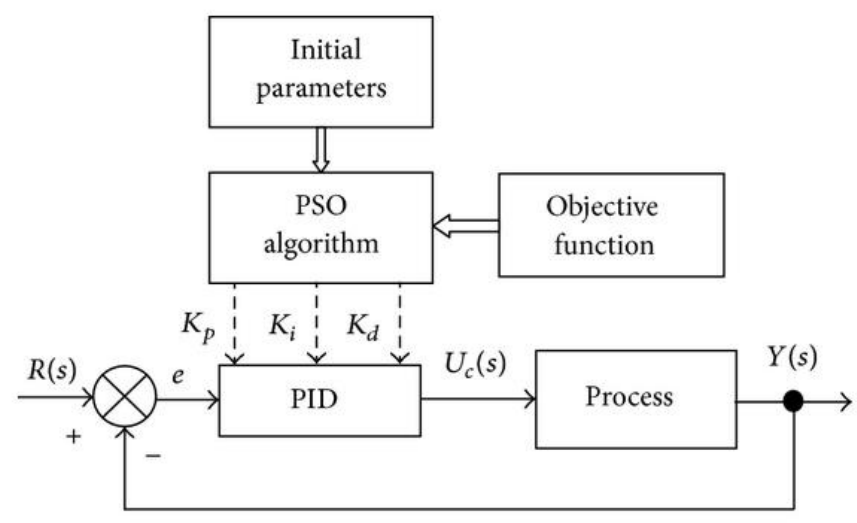

Fig.3 The block diagram of proposed PID Controller with PSO algorithms

The Particle Swarm Optimization (PSO) model consists of a swarm of particles, which are initialized with a population of random candidate solutions. They move iteratively through the d-dimension problem space to search the new solutions. Each particle has a position represented by a position vector $X_{k}^{i}$ where (i is the index of the particle), and a velocity represented by a velocity vector $V_{k}^{i}$. Each particle remembers its own best position $P_{b e s t}^{i}$. The best position vector among the swarm then stored in a vector $P_{\text {global }}^{i}$. During the iteration time k, the update of the velocity from the previous velocity to the new velocity is determined by:

$$
V_{k+1}^{i}=w V_{k}^{i}+c_{1} R_{1}\left(P_{\text {best }}^{i}-X_{k}^{i}\right)+c_{2} R_{2}\left(P_{\text {global }}^{i}-X_{k}^{i}\right)
$$


The new position is then determined by the sum of the previous position and the new velocity:

$$
X_{k+1}^{i}=X_{k}^{i}+V_{k+1}^{i}
$$

Where $R_{1}$ and $R_{2}$ are random numbers. A particle decides where to move next, considering its own experience, which is the memory of its best past position, and the experience of the most successful particle in the swarm.

\section{Results}

The transfer function using the parameter in Table.1of DC motor is:

$$
G(s)=\frac{\omega(s)}{U(s)}=\frac{0.023}{0.005 s^{2}+0.01002 s+0.000559}
$$

The simulation procedure may be summarized as follows:

- First input the DC motor data,

-Write the differential equations for the model then get the state space representation

- Get the open loop transfer function and the closed loop step response

- Finally performing the performance of PID controller by Ziegler Nichols method and PID controller by using PSO algorithm and compare the results.

The step response for open loop system and closed loop system is shown in Fig.4 and Fig.5.

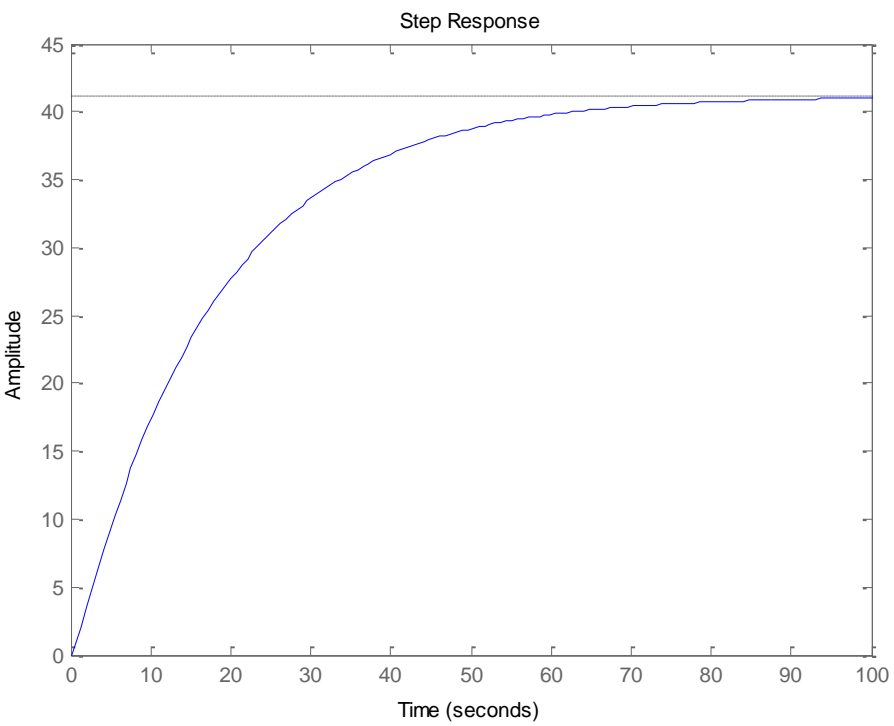

Fig.4 Step response for open loop system 


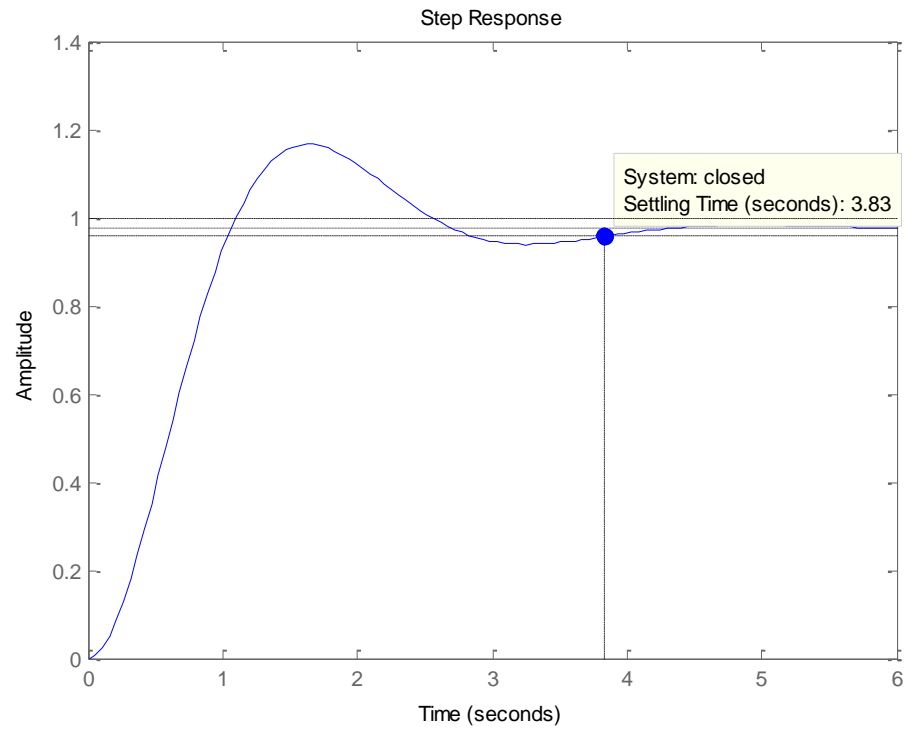

Fig.5 Step response for closed loop system

The unit step response of the system based on Zeigler-Nichols tuning method is as shown in Fig.6.

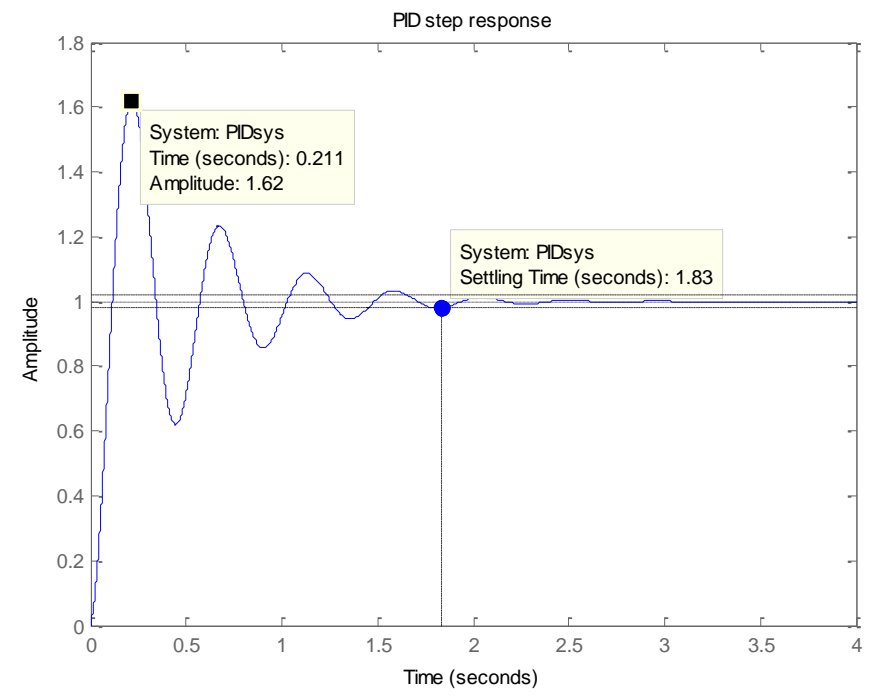

Fig.6 Step response for closed loop system with PID controller

The unit step response of the system based on PSO algorithm for $\mathrm{K}_{\mathrm{p}}=30.1256, \mathrm{~K}_{\mathrm{i}}=2.5896$ and $\mathrm{K}_{\mathrm{d}}=$ 10.1347 tuning method is as shown in Fig.7. 


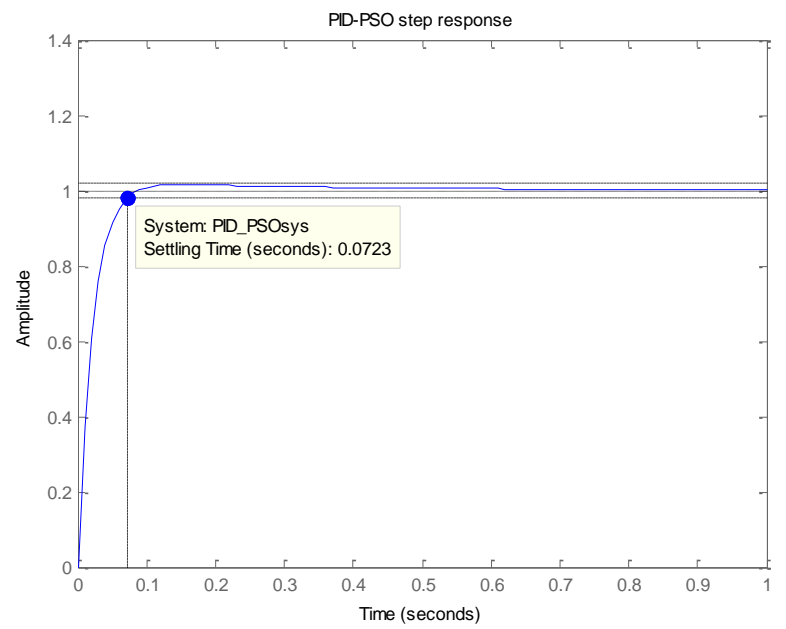

Fig.7 Step response for closed loop sy stem with PID controller

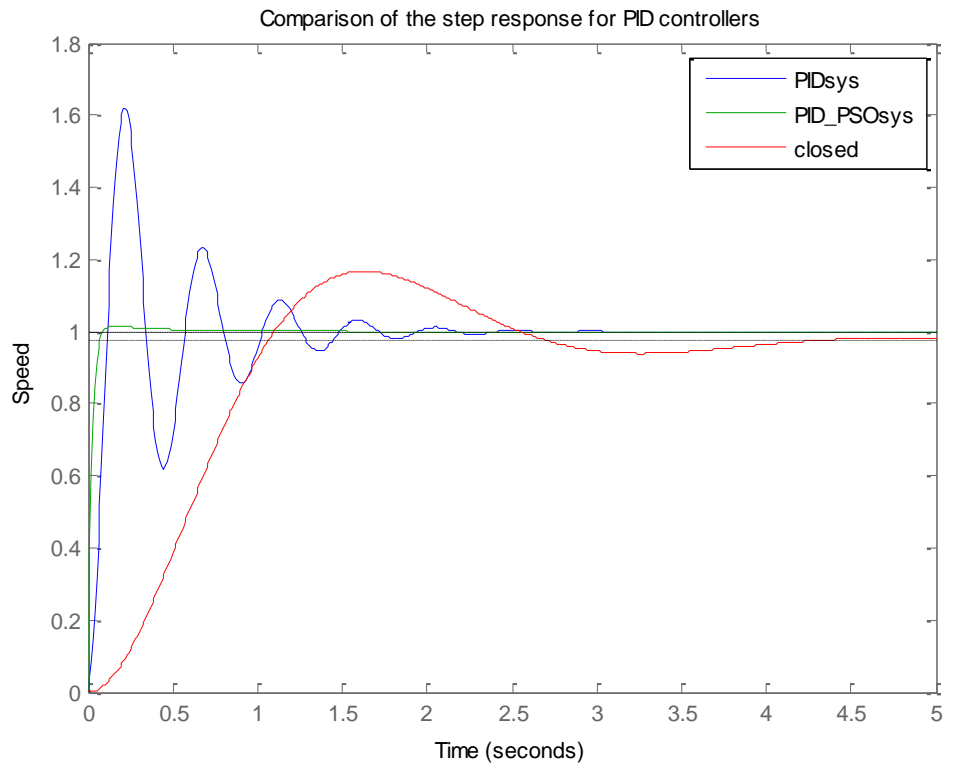

Fig.8 Comparison of closed step response, Z-N PID step response and PSO-PID step response

To show the effectiveness of the proposed approach, is made a comparison with designed of PID controller using Ziegler-Nichols method and PSO algorithm method in table 3. 
International Conference on Mechatronics Robotics and System Engineering, Nov 2015

\begin{tabular}{lcccc}
\hline \multicolumn{5}{c}{ Table.3 Comparison of the system } \\
\hline Method & $\begin{array}{c}\text { Settling time } \\
(\mathrm{sec})\end{array}$ & Overshoot $(\%)$ & Rise time (sec) & $\begin{array}{c}\text { Steady state } \\
(\%)\end{array}$ \\
\hline Closed System & 3.83 & 19.5 & 0.721 & 0 \\
Z-N PID & 1.83 & 62 & 0.0815 & 0 \\
PSO-PID & 0.0723 & 1.5 & 0.0451 & 0 \\
\hline
\end{tabular}

\section{Conclusion}

PID controllers are a widespread control solution due to their simple architecture, generally acceptable control performance and ease of use. In this work PID controller has been tuned usingZiegler-Nichols method and Particle Swarm Optimization (PSO) through simulation of DC motor speed control system. The performance of the PSO algorithm method of tuning a PID controller has been proved to be better than traditional method Ziegler-Nichols method, in terms of the system overshoot, settling time and rise time.

\section{References}

1. Zafer Bingul, Oguzhan Karahan: Tuning of Fractional PID Controllers Using PSO Algorithm for Robot Trajectory Control ;International Conference on Mechatronics, 2011,

2. M. Nasri, H. Nezamabadi and M. Maghfoori, "A PSO-Based Optimum Design of PID Controller for A Linear Brushless DC Motor", World Academy of Science, Engineering and Technology, 2007.

3. Zwe-Lee Gaing, "A particle Swarm Optimization Approach for Optimum Design of PID Controller in AVR(Automatic Voltage Regulator) System", IEEE Transactions on Energy Conversion, Vol.19, No.2, pp384-391, 2004.

4. B. Nagaraj And N. Murugananth "Soft Computing-Based Optimum Design of PID Controller For A Position Control of DC Motor", Mediamira Science Publisher, Volume 51, Number 1, 2010.

5. B. Allaoua, B. Gasbaoui, And B. Merbarki "Setting Up PID DC Motor Speed Control Alteration Parameters Using Particle Swarm Optimization Strategy", Leonardo Electronic Journal of Practices And Technologies, Issue 14, P 19-32, 2009.

6. Li Y., Ang K.H. and Chong G.C.Y. "PID Control Sy stem Analy sis and Design -Problems"IEEE Control Systems Magazine, pp. 32-41.ISSN 0272 (2006).

7. B. Nagaraj, S.Subha, B.Rampriy a: Tuning Algorithms for PID Controller Using Soft Computing Techniques, IJCSNS International Journal of Computer Science and Network Security, VOL.8 No.4, April 2008 